Institute of $\mathbf{F}_{\text {ood and }} \mathbf{A}_{\text {gricultural }} \mathbf{S}_{\text {ciences }}$

\title{
Manual de los Reglamentos del Agua de Florida: Departamento de Agricultura y Servicio al Consumidor ${ }^{1}$
}

\author{
Michael T. Olexa, Laura Minton, Dulcy Miller, y Sarah Corbett ${ }^{2}$
}

\section{Agradecimientos}

Los autores agradecen a Richard Budell de la Oficina de Política del Agua Agrícola del Departamento de Agricultura y Servicios al Consumidor de Florida. Los autores también agradecen a David H. Hammonds, Consultor del Programa de Salud Ambiental, Oficina de Programas de Aguas de Drenaje en el Sitio, del Departamento de Salud de Florida, y a Edward A. Bettinger, Consultor del Programa de Salud Ambiental, Oficina de Programas de Agua del Departamento de Salud de Florida.

\section{Sinopsis}

El Departamento de Agricultura y Servicio al Consumidor (DASC) lleva acabo funciones relacionadas con las prácticas y productos agrícolas Las responsabilidades que incluyen son:

- registro, etiquetado e inspección de fertilizantes comerciales, plaguicidas y gasolina $\mathrm{y}$ aceites.

- registro (como permisos y regulaciones) de aplicadores de plaguicidas.

- conservación del suelo y agua.

Como otras agencias del estado, el DASC esta compuesto en divisiones, cada una con una función separado. Estas incluyen:

1. Este es el documento EDIS FE075, una publicación del Department of Food and Resource Economics, Florida Cooperative Extension Service, Institute of Food and Agricultural Sciences, University of Florida, Gainesville, FL. Publicada Noviembre 2002. Por favor visite la página electrónica EDIS en http://edis.ifas.ufl.edu.

2. Michael T. Olexa, es profesor del Department of Food and Resource Economics, Florida Cooperative Extension Service, Institute of Food and Agricultural Sciences, University of Florida, Gainesville, FL; y miembro de Florida Bar; Presidente de Agricultural Law Committee of The Florida Bar; y Director del Agricultural Law Center. Laura Minton, Dulcy Miller, y Sarah Corbett son estudiantes graduadas de Levin College of Law, University of Florida, Gainesville, FL. Filiberto Reyes-Villanueva fue el traductor de la versión en ingles al español.

Esta publicación esta diseñada para proporcionar información precisa, actualizada y autorizada sobre esta material. Sin embargo, ya que las leyes, reglas administrativas y decisiones de la corte, sobre las cuales están basados, están sujetas a revisión constante; algunas partes de esta publicación podrían ser obsoletas en cualquier momento. Esta publicación es distribuida bajo el entendimiento que los autores no están involucrados en ninguna representación legal u otros servicios profesionales, y que la información contenida aquí no debe ser considerada como un substituto de una asesoria legal. Esta publicación no esta completa en proporcionar toda la información para lograr el cumplimiento de las leyes y reglamentos que gobiernan la protección del agua. Por estas razones, el uso de estos manuales por cualquier persona constituye un acuerdo para mantener libre de daño a los autores, al Florida Cooperative Extension Service, al Institute of Food and Agricultural Sciences, y a la University of Florida por cualquier demanda por responsabilidad de daños, o gastos en que pueda incurrir cualquier persona, como un resultado de hacer referencia o confianza sobre la información contenida en esta publicación. Esta publicación fue apoyada financieramente por el Florida Department of Agriculture and Consumer Services.

El Instituto de Alimentos y Ciencias Agrícolas es Un empleador que opera bajo Acción Afirmativa y provee Oportunidades Igualitarias, dedicado a promocionar la investigación, a información educativa y otros servicios, únicamente a los individuos e instituciones que operan baj discriminación sin considerar color, raza, sexo, edad, incapacidad u origen. Para más información sobre como obtener otras publicaciones de la extensión, comuníquese con la oficina de Servicio de Extensión de su condado. Servicio de Extensión de la Florida / Instituto de Alimentos y Ciencias Agrícolas / Universidad de la Florida / Christine Taylor Waddill, Decana. 
- División de Servicios de Agricultura y el Medio

Ambiente regula y emite permisos para el control de operaciones de plagas y provee asistencia a los Distritos de Conservación de Suelo y Agua. Dentro esta división esta la Oficina de Plaguicidas, que registra los plaguicidas y supervisa los programas de plaguicidas que están relacionados con la protección de las aguas subterráneas, trabajadores agrícolas y especies amenazadas. La división también incluye la Oficina de Conservación de Suelo y Agua (ver la sección Prácticas

Ambientalmente Seguras).

- División de Estándares es responsable por el petróleo y las inspecciones de los tanques subterráneos. Sus funciones incluyen análisis de la calidad de combustible y la seguridad de la instalación distribuidora del combustible la escala y exactitud de los utensilios de medición.

- División de Bosques maneja los recursos forestales. Dentro de esta división está la Oficina de Planificación de Servicios la cual incluye la Sección de Protección de Aguas Divisorias (SPAD). La (SPAD) ofrece servicios profesionales de hidrología (ciencia del uso del agua) para el público y otras agencias del estado. Es también responsable del desarrollo de elementos de silvicultura (forestal) del Plan de la Calidad del Agua del Estado (discutido bajo la Sección de DMA). Lo mas importante, la SPAD monitorea el impacto de la reglamentación del agua en los bosques y podría ser la mas útil para ayudar al agricultor en el manejo de cualquier recurso forestal que pueda poseer.

- División de Administración proporciona servicios de apoyo a toda las demás divisiones. Esta división incluye la Oficina para la Aplicación de Leyes Agrícolas, la cual lleva a cabo la inspección de los productos agrícolas. 